\title{
Escolas de tempo integral e atividades extracurriculares: universos à espera da Psicologia brasileira
}

(Full time school and extracurricular activities: universes waiting of the Brazilian Psychology)

(Escuelas de tiempo completo y actividades extracurriculares: universes espera Psicología de Brasil)

Neyfsom Carlos Fernandes Matias*

\begin{abstract}
Resumo
Observa-se que, no Brasil, diversas ações vêm sendo desenvolvidas com o intuito de se implantar uma educação em tempo integral. Sabe-se que as atividades ligadas ao esporte, às artes e culturais podem contribuir significativamente nesse sentido. Com base nisso, este artigo apresenta algumas iniciativas que visavam à execução de escolas de tempo integral e como as atividades extracurriculares podem ser úteis na efetivação de uma educação em tempo integral. O objetivo deste estudo foi o de verificar o que já se tem publicado sobre as escolas de tempo integral e atividades extracurriculares, desde uma pesquisa bibliográfica, nos periódicos "Psicologia: teoria e pesquisa"; "Psicologia: reflexão e crítica"; "Psicologia escolar e educacional". As consideraçôes finais apontam que o estudo sobre as atividades extracurriculares e escolas de tempo integral ainda é embrionário no Brasil e que urge a realização de pesquisas empíricas sobre atividades extracurriculares no País.
\end{abstract}

Palavras-chave: escola de tempo integral; atividades extracurriculares; criança e adolescente.

\begin{abstract}
It has been noted that in Brazil, lots of actions has been developing in order to deploy a full - time education. It has been known that the activities related to sports, arts and cultural can contribute significantly in this way. From that, this article shows some initiatives that had targeted the execution of full time schools and how the Extracurricular Activities can be useful in the realization of a full time education. The aim of this study was to verify what already has been published about Full Time Schools and Extracurricular Activities, from a reference research in the periodicals Psicologia: Teoria e Prática; Psicologia: Reflexão e Crítica;
\end{abstract}

Texto recebido em março de 2009 e aprovado para publicação em outubro de 2009.

* Mestrando em Psicologia pela Universidade Federal de Minas Gerais. E-mail: neyfsom@yahoo.com.br. 
Psicologia Escolar e Educacional. The final considerations point that the study about the Extracurricular Activities and the full time schools are still embryonic in Brazil, and that urges the realization of empirical researches about Extracurricular Activities in the country.

Key-words: full time school; extracurricular activities; child and adolescents.

\section{Resumen}

En Brasil, diversas acciones han sido desarrolladas con la intención de implantar de la Educación de Tiempo Completo. Se sabe que las actividades vinculadas a desportes, artes y cultura pueden contribuir significativamente en esta dirección. A partir de esto, este artículo presenta algunas iniciativas que tienen como objetivo la ejecución de Escuelas de Tiempo Completo y cómo las Actividades Extracurriculares pueden ser útiles en la efectuación de una educación de tiempo completo. Este estudio tuvo el objetivo de verificar lo que ya existe publicado sobre las Escuelas de Tiempo Completo y Actividades Extracurriculares, a partir de una investigación en la bibliografía de los siguientes periódicos: Psicologia: Teoria e Pesquisa; Psicologia: Reflexão e Crítica; Psicologia Escolar e Educacional. Las consideraciones finales indican que el estudio sobre las Actividades Extracurriculares y Escuelas de Tiempo Completo es todavía embrionario en Brasil y que hay urgencia en la realización de investigaciones empíricas sobre actividades extracurriculares en el país.

Palabras llave: escuela de tiempo completo; actividades extracurriculares; niños y adolescentes.

\section{Introdução}

A

ideia de que é por meio da educação que uma nação se constrói é universal. Consoante a isso, a Lei de Diretrizes e Bases para a Educação (LDB) (Brasil, 1996) destaca que "a educação abrange os processos formativos que se desenvolvem na vida familiar, na convivência humana, no trabalho, nas instituições de ensino e pesquisa, nos movimentos sociais e organizações culturais". Ou seja, "a educação, na sua acepção mais ampla, tem objetivos que ultrapassam o raio de ação da escola” (Soares, 2007, p. 136).

Tendo em vista que a educação não acontece somente na esfera escolar e que ela pode e também é promovida fora da escola, este artigo tem como tema as ações realizadas em contextos para além da sala de aula formal. Mais precisamente na relação entre atividades extracurriculares (Mahoney, Harris \& Eccles, 2006), também denominadas de ações socioeducativas (Carvalho \& Azevedo, 2005), e educação de tempo integral. 
Com base no destaque feito pela LDB (Brasil 1996) de que a educação ultrapassa as fronteiras da escola e da articulação desse ponto com as ações realizadas por crianças e adolescentes fora do contexto escolar, é que surgem algumas indagações para a construção deste artigo. Os questionamentos se referem ao que vem sendo produzido acerca do tema em alguns periódicos brasileiros de Psicologia, no que tange à produção de estudos que tenham como objeto as atividades extracurriculares, impactos dessas ações sobre o desenvolvimento humano e nas contribuições dessa área para a educação de tempo integral.

É notório, no senso comum, a opinião de que a participação de crianças e adolescentes (sobretudo as que vivem nas comunidades menos favorecidas economicamente) em programas sociais, no horário alternado ao da escola ou nas escolas de tempo integral, justifica-se pela possibilidade de proteção desse público, devido a situações de vulnerabilidades sociais, e, sobretudo, para a não inserção dos jovens no mundo do crime. Diante disso, este trabalho apresenta considerações sobre o fato de que as escolas de tempo integral, como políticas públicas, têm sido executadas no Brasil pautadas na premissa de que essa é uma ação para o público de áreas em que a vulnerabilidade social é a principal característica; no sentido de ser mais um espaço de assistência do que de possibilidades para aprender e se desenvolver. Contrário a isso, este texto destaca que ações complementares à escola ou escolas de tempo integral justificam-se não só pelo seu caráter protetor, mas também pelos impactos no desenvolvimento, em diversos âmbitos, do público que participa dessas atividades.

Sabe-se que a Psicologia tem conhecimento sólido para contribuir no desenvolvimento de uma melhor educação. A partir disso, objetivouse identificar a produção dessa área sobre os impactos das atividades extracurriculares e escolas de tempo integral em três periódicos científicos. Os dados coletados são apresentados e, em seguida, discutidos. Encerra-se o texto com as considerações finais, com destaque para urgência da realização de estudos empíricos sobre os impactos das atividades extracurriculares no desenvolvimento infantil e adolescente no Brasil.

\section{Experiências de políticas públicas no ensino fundamental para o atendimento a crianças e adolescentes em tempo integral}

O desenvolvimento de ações por meio da arte, do esporte, da brincadeira e da recreação como complemento da escola formal, ao longo dos anos, tem tido destaque na escola, sobretudo ao se elencarem os estudos que discutem as 
ações que buscaram a implantação da educação de tempo integral no Brasil (Cavaliere \& Coelho, 2003). Nesse sentido, observa-se que houve iniciativas no âmbito das políticas públicas, cujo foco principal era a criação de escolas em tempo integral, que foram introduzidas em alguns Estados e se expandiram para todo o território nacional. Havia uma forte tendência à implantação de escolas que tinham como objetivo proporcionar um espaço de proteção para crianças e adolescentes o dia todo, com atividades diferenciadas.

Esse é o caso, por exemplo, da experiência desenvolvida por Anísio Teixeira, em Salvador, na Bahia, no ano de 1962 (Costa, 1991); dos Centros Integrados de Educação Pública - CIEPs, no Rio de Janeiro, em 1985 (Cavaliere \& Coelho, 2003; Brandão, 1989); e também dos Centros Integrados de Apoio à Criança - CIACs, programa do governo federal para implantação em todo Brasil, a partir de 1992 (Kramer, 1991; Pont, Fontenelle \& Bernardi, 1991).

Ao analisar as experiências de tempo integral desenvolvidas pelos CIEPs e CIACs, Kramer (1991) e Mignot (1991) destacam que, com essas propostas, a escola passa a ter outras funções, que são cuidar, com atendimento médico, odontológico e outros, das crianças e dos adolescentes. No entanto, esse modelo de escola que atende a todas as demandas, principalmente às de crianças e adolescentes provenientes de comunidades desfavorecidas economicamente, foi questionado. Com as críticas, surgiram algumas previsões que podem ser exemplificadas nas palavras de Kramer (1991, p. 461), que presumia "a morte da escola como espaço de emancipação cultural, a cristalização da escola como serviço de assistência". Entretanto, com as mudanças de governo no Estado do Rio de Janeiro e no âmbito nacional, a escola não se consolidou em um espaço de serviço de assistência, como previsto nas propostas dos CIEPs e CIACs.

Em São Paulo, durante os anos de 1986 a 1993, também foi executada uma política pública que visava a implementar a educação em tempo integral, ligada ao governo do Estado, diferente da linha dos centros integrados, denominada de Programa de Formação Integral da Criança (Profic). Segundo Giovanni \& Souza (1999, p. 70), esse programa "procurou estender o tempo de permanência das crianças pobres na escola e expandir as condiçóes para seu melhor desempenho na aprendizagem" (grifo nosso). A ideia não era a de aumentar as atividades escolares, mas sim desenvolver atividades artísticas, recreativas, esportivas e proporcionar um reforço na aprendizagem.

Para a implantação desse programa, os seus planejadores buscaram "deliberadamente parceiros no chamado terceiro setor e no nível mais 
descentralizado do poder público: o município" (Giovanni \& Souza, 1999, p. 72) (grifo dos autores). Um dos pontos de evidência dessa política pública foi a realização de parcerias, com destaque para as organizaçõos não governamentais (ONGs), sobretudo no que tange ao uso de espaços ociosos nos locais onde o programa foi desenvolvido e ao aproveitamento de recursos humanos e materiais encontrados nesses locais, estes usados de modo renovado (Giovanni \& Souza, 1999).

Diferentemente dos CIEPs e CIACs, o Profic não tinha como intuito a construção de obras faraônicas para a realização de suas ações. Ou seja, o seu diferencial é que foi "a primeira experiência em educação integral que se utilizou de parceria como uma estratégia explícita e deliberada para o aproveitamento de recursos preexistentes" (Giovanni \& Souza, 1999, p. 72).

A avaliação dos impactos do Profic mostra que o programa obtinha resultados positivos e que essa experiência pode ser modelo para se programar uma educação de tempo integral, pois,

[...] a taxa de evasão entre os alunos do Profic era menor do que a taxa de evasão no conjunto das escolas em 82,3\% [...]. Da mesma forma, em 84,5\% das escolas, o índice de retenção era menor entre os alunos do Profic. Os professores (97\%) afirmavam que houve melhoria no rendimento escolar dos alunos [...]. Do ponto de vista das relações das crianças com seu grupo, metade dos professores informava que houve melhoria, ficaram mais sociáveis (40\%) e tornaram-se mais bem humoradas $(76 \%)$. As crianças (83\%) do Profic apresentaram empenho na realização das tarefas escolares, bem como aumentaram a capacidade de tomar iniciativas (82\%) e de se expressarem (90\%) (Giovanni \& Souza, 1999, p. 104).

Pela experiência do Profic, pode-se observar que as atividades realizadas fora do âmbito escolar causam impactos significativos no desenvolvimento da criança e do adolescente na escola. Porém, sabe-se que a estrutura, os processos e o conteúdo das salas de aula ainda são, sem sombra de dúvida, as principais influências sobre a realização da educação formal. No entanto, qualidades individuais dos estudantes, de seus familiares e de como crianças e adolescentes usam seu tempo fora do âmbito escolar podem exercer fortes influências sobre o seu desenvolvimento acadêmico e de quão bem estão na escola (Cooper, Valentine, Nye \& Lindsay, 1999).

Nesse sentido, uma ação para além da sala de aula, fora do horário escolar, justifica-se pelo seu caráter de proteção social e porque possibilita outras oportunidades para crianças e adolescentes se desenvolverem. Isso já demonstra a importância das atividades extracurriculares como parceiras 
no planejamento e execução de escolas ou educação em tempo integral. A LDB (Brasil, 1996), nas disposiçôes gerais do Título IX, parágrafo $5^{\circ}$, aponta que "serão conjugados todos os esforços, objetivando a progressão das redes escolares públicas urbanas de ensino fundamental para o regime de escolas de tempo integral”.

Com intuito de contribuir no empenho de se implantarem escolas ou uma educação em tempo integral, é importante que sejam levados em consideração estudos que forneçam informações para subsidiar essa ação. E mais: que possam, de certa maneira, apontar soluçóes, por exemplo, para o problema da falta de espaços físicos nas escolas, que impedem a ampliação de sua jornada, destacando o quanto pode ser útil o uso de contextos diferenciados (Guará, 2007; Centro de Estudos e Pesquisas em Educação, Cultura e Ação Comunitária, 2003).

A com base nisso, a próxima seção apresenta as atividades extracurriculares, com destaque para seus impactos, no sentido de demonstrar que programas executados no contraturno escolar são importantes muito mais pelos seus efeitos do que pela proteção que proporcionam ao público atendido. Fato que deve ser levado em consideração ao se pensar em uma educação em tempo integral.

\section{Atividades extracurriculares: impactos e contribuições para a escola de tempo integral}

As atividades extracurriculares são ações desenvolvidas em ambientes como quadras, salas de jogos, teatros, bibliotecas, praças e outros, antes ou após o período de aula na escola, cujos objetivos não necessariamente estejam ligados à educação formal (Mahoney, 2000; Mahoney, Harris \& Eccles, 2006). Elas podem ser estruturadas com encontros e lugares definidos, acontecer regularmente, como aulas de música, esportes, atividades recreativas, de lazer, reforço escolar, apoio ao para casa, entre outras atividades, conduzidas por profissionais com experiência sobre a atividade em questão. No Brasil, observase que muitas ONGs têm desenvolvido projetos, cujo foco é o atendimento a crianças e adolescentes no contraturno escolar, por meio de aulas de teatro, esportes, informática, entre outras (Centro de Estudos e Pesquisas em Educação, Cultura e Ação Comunitária, 2003).

As açōes socioeducativas conjugam educação e proteção social, ao atender crianças, adolescentes e jovens, com o oferecimento de atividades lúdicas, artísticas e esportivas. A maioria dessas ações visa ao público que se encontra em situação de vulnerabilidade social. Em alguns casos, elas são realizadas 
em parceria com o governo municipal, estadual ou federal e têm caráter de política pública (Carvalho \& Azevedo, 2005).

Não só as atividades extracurriculares e ações socioeducativas, mas o que crianças e adolescentes fazem fora do ambiente escolar mostram-se como um campo de pesquisa com inúmeras questóes a serem respondidas, tais como quais são as influências das ações extraclasses para o ajustamento emocional, na relação com a instituição escolar, não inserção no mundo do crime, desempenho acadêmico e desenvolvimento cognitivo, entre outras.

Um número crescente de pesquisadores têm voltado sua atenção para o que os públicos infantil, adolescente e juvenil realizam para além dos muros escolares (Mahoney, 2000; Posnell \& Vandell, 1999, 1994; Eccles, Barber, Stone \& Hunt, 2003; Mahoney \& Cairns, 1997).

Posner e Vandell (1999) destacam que crianças e adolescentes que participam de atividades extracurriculares apresentam melhor ajustamento emocional quando comparadas às que não participam, assistem a menos televisão, fazem poucas atividades não estruturadas e gastam menos tempo em atividades caracterizadas como trabalho infantil. No estudo desses autores, as açôes fora da escola eram estruturadas e tinham uma organização própria. Ofereciam ajuda no dever de casa, desenvolviam atividades recreativas e esportivas, como basquete e futebol, que aconteciam três ou mais vezes por semana, no final do período escolar (Posner \& Vandell, 1994, 1999).

Estudos longitudinais mostram que os impactos das atividades extracurriculares estão presentes para além do período de permanência nessas açôes. Mahoney (2000) descreve um estudo que teve como principal objetivo examinar a relação entre a participação de crianças e adolescentes em atividades extracurriculares e o padrão de comportamento antissocial da infância até a juventude.

Os jovens foram entrevistados quando tinham aproximadamente 10 e 13 anos e novamente quando estavam com idade de 20 e 24 anos. As atividades extracurriculares identificadas nesta pesquisa foram divididas nos seguintes grupos: atléticas (baseball, basquete, futebol), assistenciais (assistente de biblioteca), artes (clube de arte, coral, teatro) e acadêmicas (clube de história, francês e negócios) (Mahoney \& Cairns, 1997).

Os resultados desses e de outros estudos mostram que a participação em atividades extracurriculares promove oportunidades para criar uma conexão positiva e voluntária com a instituição escolar (Mahoney, 2000; Mahoney \& Cairns, 1997). Mahoney (2000) aponta que o envolvimento em atividades 
extracurriculares pode estar associado a reduzidas taxas de abandono escolar e de criminalidade entre meninos e meninas que vivem sob elevado risco no seu desenvolvimento.

Cooper, Valentine, Ney \& Lindsay (1999) encontraram resultados semelhantes aos de Mahoney (2000) e de Posner \& Vandell $(1994,1999)$ no estudo que teve como objetivo detectar a relação entre atividades após a escola e o desempenho acadêmico de adolescentes. Esses pesquisadores analisaram cinco tipos de atividades extracurriculares: dever de casa, assistir à televisão, trabalho, participação em clubes acadêmicos, de esportes e outras que dizem respeito a atividades em grupos estruturados, como escoteiros e ligados à Igreja.

A fim de verificar o desempenho acadêmico dos adolescentes, Cooper, Valentine, Ney, \& Lindsay (1999) relacionaram os dados coletados com os resultados de um programa de avaliação, administrado pelo Estado norteamericano do Tennessee (Tennessee Comprehensive Assessment Program - TCP). Esse teste avaliou o desenvolvimento cognitivo no que tange ao vocabulário, aprendizagem de leitura e cálculos matemáticos, expressão da linguagem, fala, ciências, estudos sociais e habilidades de estudo.

Os principais resultados encontrados nessa pesquisa mostram que a participação em atividades extracurriculares, em grupos estruturados, relaciona-se positivamente com os escores das variáveis avaliadas pelo TCAP. Porém o mesmo não aconteceu na comparação entre atividades ligadas a trabalho e assistir à televisão. Os autores comprovaram a hipótese de que fazer o dever de casa e participar de atividades extracurriculares organizadas é um indício positivo de desenvolvimento escolar. As investigações de Posner \& Vandell (1999) e de Cooper, Valentine, Ney \& Lindsay (1999) destacam que assistir a menos televisão, fato que pode acontecer com a inserção de crianças e adolescentes em programas extracurriculares, pode contribuir, em certa medida, para um melhor desempenho em atividades escolares.

Destaca-se que, pela importância desses e de outros achados (Pierce, Hamm \& Vandell, 1999; Matias, 2007), o impacto das atividades extracurriculares para o desenvolvimento integral da criança e do adolescente é extremamente relevante e frisa o quanto elas podem ser importantes ao se pensar em uma educação de tempo integral. Faz-se importante enfatizar que os estudos sobre atividades extracurriculares apresentados mostram dados de contextos diferenciados. Diante disso, surgiu o objetivo desse estudo, que foi o de pesquisar o que tem sido produzido sobre atividades extracurriculares e educação em tempo integral na área da Psicologia e quais as contribuições 
desses trabalhos para se pensar em políticas públicas para a infância e adolescência, tanto na educação como no desenvolvimento humano.

\section{Método}

Esta pesquisa foi realizada em três revistas científicas de Psicologia. Em dois periódicos de cunho generalista com trabalhos de diferentes campos da área, cuja periodicidade é quadrimestral, nacionais classificados como nacional e internacional A pela CAPES, em 2007: "Psicologia: teoria e pesquisa", publicação do Instituto de Psicologia da Universidade de Brasília-DF, publicada desde 1985; e "Psicologia: reflexão e crítica", de responsabilidade do Programa de Pós-graduação em Psicologia da Universidade Federal do Rio Grade do Sul, editada desde 1986.

A terceira foi "Psicologia escolar e educacional", revista com periodicidade semestral, avaliada em 2007 pela CAPES com o conceito A nacional, vinculada à Associação Brasileira de Psicologia Escolar e Educacional, publicada desde 1996. A opção por essa revista teve a finalidade de verificar a hipótese de que, sendo um periódico da área da Psicologia escolar e educacional, o número de publicações contendo questôes sobre as atividades extracurriculares e escola de tempo integral apareceriam de forma mais significativa.

Após uma pesquisa exploratória nos periódicos e a partir da bibliografia sobre as atividades extracurriculares e escolas de tempo integral, foram traçados alguns critérios para a seleção de textos a serem analisados e que fariam parte da amostra. Todos os trabalhos que tivessem no título palavras-chave como programas, extracurricular(es), oficina(s), contraturno, extraescolar, projeto(s), ação socioeducativa, jornada ampliada, para casa ou trabalho de casa, centros, ONGs, crianças, adolescentes, estudantes, tempo integral, professores e escola poderiam ser selecionados para análise.

Desde a detecção de um ou mais desses termos no título, realizou-se uma leitura no resumo do artigo. Caso houvesse relação ou destaque referente a atividades extracurriculares ou escolas de tempo integral, o texto seria selecionado para compor a amostra. Ao final da investigação exploratória, observou-se que os temas ainda são embrionários nas publicaçôes escolhidas para pesquisa. Diante disso, traçou-se como objetivo que essa pesquisa levantasse trabalhos que tratassem de atividades extracurriculares como um todo, na sua acepção mais ampla, ou seja, desde os artigos que relatassem questôes sobre o que crianças e adolescentes fazem após ou antes da escola e ações realizadas por esse público, que não estivessem ligadas à escola diretamente, até programas estruturados que atendessem crianças e 
adolescentes no contraturno, como política pública ou não, e pesquisas cujos participantes estavam inscritos em algum programa ou realizavam algum tipo de atividade extracurricular. O critério principal e delimitador era o de que, em alguma medida, o artigo tratasse de algo relacionado a atividades extracurriculares ou escolas de tempo integral em consonância com o apresentado neste trabalho.

Apesar dessa amplitude de atividades extracurriculares, trabalhos, cujo tema refere-se a brincadeiras e jogos específicos ligados a aspectos que não se relacionam de alguma maneira com a escola ou que visa a investigaçóes ligadas apenas aos aspectos cognitivos, não foram destacados. Tal demarcação foi definida devido ao fato de o foco desses outros trabalhos não terem relação com atividades extracurriculares ou não apresentarem contribuições para ações extracurriculares ou escolas de tempo integral.

O ponto principal era o de que fosse possível destacar ao menos uma contribuição para a educação em tempo integral, proveniente de outros contextos para além da escola formal. Apesar disso, caso algum trabalho tivesse no título alguma palavra-chave ligada ao brincar, por exemplo, o seu resumo seria lido a fim de observar se havia ou não relação com os temas de destaque desse trabalho. Em caso positivo, o artigo faria parte da amostra. Ou seja, trabalhos originais que mostrem resultados de pesquisas ou discussões teóricas. Não constaram como objeto desta pesquisa relatos de experiências, sugestôes de atividades, comunicações, resenhas, entrevistas, editoriais, apresentações, debates, homenagens (in memoriam e honra ao mérito), documentos, notas bibliográficas.

O período de publicação, número de volumes e artigos publicados e quantidade de trabalhos encontrados relacionados aos temas são apresentados por periódico. Foram criadas categorias de análise, como sugere Bardin (1988) no procedimento de análise do conteúdo, a fim de nortear a investigação. Nesse sentido, destacaram-se dos artigos os seguintes dados: questóes investigadas; participantes das pesquisas, faixa etária e nível socioeconômico; características das atividades extracurriculares apresentadas; e principais resultados.

\section{Resultados}

A) Revista Psicologia: teoria e pesquisa - A investigação abrangeu os trabalhos publicados no período de 1985 (v. 1, n. 1) até 2008 (v. 24, n. 3), em que se observou a publicação de 24 volumes que, entre suplementos, números regulares e especiais, abrangem 78 exemplares, contendo 765 artigos. Destes, somente três foram destacados por se tratarem de trabalhos relacionados às atividades extracurriculares, que são os artigos de Marturano (1999), Poletto, 
Wagner e Koller (2004), Okano \& Loureiro (2008).

Marturano (1999) investigou os recursos específicos do ambiente familiar, que favorecem o desempenho escolar, em uma amostra composta de 100 crianças, com idade de 7 a 12 anos, provenientes de famílias de nível socioeconômico baixo. Essa pesquisa teve como objetivo "verificar a disponibilidade de recursos associados ao desempenho acadêmico em famílias de crianças encaminhadas por dificuldades na aprendizagem escolar" (Marturano, 1999, p. 136). Lição de casa, atividades com horário definido, ajuda em casa, entre outras, foram as atividades extracurriculares destacadas por essa pesquisa. Os resultados do trabalho apontam para o fato de que o avanço do que é aprendido na escola, ressaltado pela ausência "de atraso ou pela qualidade da produção escrita, está associada à supervisão e à organização das rotinas no lar, a oportunidades de interação com os pais e à oferta de recursos no ambiente físico" (Marturano, 1999, p. 140).

Poletto, Wagner \& Koller (2004, p. 244) discutem a questão da resiliência com o desenvolvimento infantil de crianças que cuidam de seus irmãos menores. Apesar de o estudo não abordar as atividades extracurriculares diretamente, a amostra para a pesquisa foi composta por "quatro meninas, com idade entre 8 e 12 anos, de nível socioeconômico baixo”. Embora frequentem um programa de uma ONG que atende crianças e adolescentes em horário alternativo ao da escola, elas ficavam "em casa no período extraescolar, realizando atividades domésticas e com a responsabilidade de cuidar de irmãos menores" (p. 244). Sendo que as principais atividades desenvolvidas pelas participantes, além de irem à escola, eram "tarefas domésticas, tais como: limpar e arrumar a casa, lavar a roupa, preparar as refeições da família, além de responsabilizarem-se pelos cuidados de seus irmãos menores" (p. 245). Os resultados desse estudo apontam para o fato de que a "implementação de programas de intervenção junto a esses grupos de crianças em situação de risco pode potencializar e favorecer o desenvolvimento da resiliência" (p. 248).

Okano \& Loureiro (2008, p. 288) objetivaram verificar "o valor de proteção de um programa de suporte psicopedagógico denominado de ensino alternativo, que consiste em uma dinâmica pedagógica que acontece dentro da escola, em horário extraturno, destinado aos alunos com dificuldades selecionados para atendimento". Essa ação fazia parte de um programa desenvolvido pela Superintendência Educacional da Secretaria de Estado da Educação de Minas Gerais e "se assemelha aos programas de classes de reforço" (p. 288). Participaram do estudo 48 crianças, com idade entre 7 e 12 anos, de nível socioeconômico predominantemente de classe C. Os 
resultados desse estudo apontam "que a frequência ao programa de suporte pode ter contribuído para a superação das dificuldades comportamentais" e "melhora nas autopercepções relativas ao status intelectual" (p. 292) por parte dos sujeitos participantes.

B) Revista Psicologia: reflexão e crítica - A pesquisa ocorreu em todos os periódicos do período de 1996 (v. 1, n. 1) até 2008 (v. 21, n. 3), com exceção dos anos 1990 e 1991, em que revista não foi publicada. Foram analisados 21 volumes que, entre números regulares e especiais, compreendem 49 exemplares, com um total de 696 artigos. Destes, destacam-se quatro artigos que se referem às atividades extracurriculares, que são os de Bandeira, Koller, Hutz \& Forster (1996); Cordeiro, Menezes \& Castro (2002); Okano, Loureiro, Linhares \& Marturano (2004); Sarriera, Tatim, Coelho \& Busker (2007).

Bandeira, Koller, Hutz \& Forster, L. (1996, p. 185) pesquisaram os impactos "de um projeto profissionalizante no desenvolvimento psicossocial" de 40 adolescentes, com idade entre 13 e 17 anos, de nível socioeconômico baixo. O estudo investigou "inteligência, aspectos emocionais, autoestima, maturação perceptomotora, motivação, habilidades e interesses profissionais, relacionamento familiar e escolar" do público participante. No caso desse trabalho, a atividade extracurricular era o "Projeto Oficina-Escola da Empresa de Trens Urbanos de Porto Alegre (Trensurb)” (p. 190), em que "as principais atividades são: mecânica, manutenção, eletricidade, [...] auxiliar de serviços gerais e de escritório" (p. 189), entre outras. Além disso, os adolescentes participavam de ações complementares "de reforço escolar, cultura, artes, lazer, esporte, saúde, higiene” (p. 189). Eles recebiam também uma bolsa de meio "salário mínimo por mês, uniformes, alimentação e algum material escolar" (p. 189). Os resultados desse estudo apontam que o envolvimento de adolescentes em atividades de recreação ou profissionalizantes "é um fator importante para o seu desenvolvimento" (p. 196). Bandeira e cols. (1996, p. 196) apontam ainda que "as mudanças ocorridas em aspectos psicossociais da vida dos adolescentes participantes do projeto Oficina-Escola mostram como essa experiência foi benéfica para o grupo" que sofreu transformações "em suas vidas, pela oportunidade que lhes foi dada” (p. 204).

Cordeiro, Menezes \& Castro (2002) realizaram um estudo cujo objetivo foi investigar "a construção e a reconstrução das experiências destes sujeitos na cidade" (p. 53). Crianças e adolescentes, de 9 a 14 anos, de nível socioeconômico baixo, participantes de atividades desenvolvidas por uma ONG, são o público desse trabalho. As autoras da pesquisa destacam que "as oportunidades de aprendizagem da criança e do jovem não se atêm aos domínios da casa e da 
escola” (p. 53). No entanto, Cordeiro, Menezes e Castro não apontam em que ocasiōes seriam essas de aprendizagem, que rompem os limites escolares e familiares. Os resultados apontam que as crianças têm capacidade de analisar criticamente suas experiências na cidade.

Okano, Loureiro, Linhares \& Marturano (2004) são autoras de um trabalho que avaliou o autoconceito de 40 crianças, de 7 a 10 anos, de baixo nível socioeconômico, que participavam de uma atividade fora do tempo escolar, que propiciava o suporte psicopedagógico como ferramenta para solucionar problemas de aprendizagem de alunos com dificuldades escolares, um projeto ligado à Secretaria de Estado da Educação do Estado de Minas Gerais. Essa ação, desenvolvida em horário extraclasse, é a mesma descrita no trabalho de Okano \& Loureiro (2008). Os resultados desse estudo apontam que crianças com dificuldades escolares apresentaram escores de autoconceito global, status intelectual e popularidade significativamente menores do que as que não têm.

Sarriera, Tatim, Coelho, \& Busker (2007) pesquisaram como adolescentes de classe popular usam o tempo livre. Participaram da pesquisa 159 pessoas, com idade entre 12 e 18 anos, de nível socioeconômico baixo. As atividades realizadas pelos adolescentes, durante a semana, destacadas no estudo, são "atividades de rotina, como descanso, higiene, alimentação, [...] atividades escolares extraclasse". Há também o uso de parte do tempo livre em deslocamentos e atividades diárias (p. 364). Os resultados dessa pesquisa apontam para a falta de alternativas de lazer e pouco acesso "a atividades artísticas, culturais e esportivas para os adolescentes pesquisados. Verifica-se a predominância do uso do tempo livre em atividades não estruturadas" (p. 366) por esse público, o que o coloca em situação de "vulnerabilidade com relação a comportamentos de risco, especialmente o envolvimento com drogas lícitas e ilícitas e a violência juvenil na forma de brigas e enfrentamentos" (Sarriera, Tatim, Coelho \& Busker, 2007, p. 366).

C) Revista Psicologia escolar educacional - Nesse periódico, a pesquisa foi realizada no período de 1996 (v. 1, n. 1) até 2008 (v. 12, n. 1). Foram analisados 12 volumes que, entre os números regulares e especiais, compreendem 26 exemplares, com um total de 218 artigos, dos quais apenas dois têm conteúdos que se referem a atividades extracurriculares. São os trabalhos de Alencar, Feldhusen \& French (2004) e Rosário, Baldaque, Mourão, Nuñez, GonzálezPienda et al. (2008).

Alencar, Feldhusen $\&$ French (2004) tiveram como objetivo detectar quais os talentos que estudantes se autoatribuem, que tipos de profissóes querem 
exercer, personalidades que admiram e participação em atividades ou cursos relacionados aos seus talentos. Participaram da pesquisa 111 adolescentes e jovens, com idade entre 6 e 19 anos; a situação socioeconômica não é apresentada pelos autores. Os participantes relataram participar de atividades extracurriculares de esportes, canto, dança, aulas de instrumentos musicais, teatro, computação, artes visuais e escultura. Além dessas, surgiram ainda as acadêmicas, Matemática, Ciências e liderança. Os resultados desse estudo constituem-se como uma expansão de outra pesquisa realizada nos Estados Unidos. Porém os dados foram coletados no Brasil, em uma cidade satélite de Brasília-DF. Não há destaque para a relação entre as atividades extraclasse realizadas pelos participantes com outras questôes para além da escolha profissional deles.

Rosário, Baldaque, Mourão, Nuñez, González-Pienda et al. (2008) realizaram um estudo, cujo objetivo foi analisar o poder preditivo da autoeficácia e dimensões relacionadas ao para casa, sobre o rendimento em Matemática, "que é por vezes incluído na categoria de atividade extracurricular quando se toma por unidade de análise, não a tarefa prescrita pelo professor, mas o contexto em que esta é realizada" (Rosário, Baldaque, Mourão, Nuñez, González-Pienda et al., 2008). "Participaram do estudo 794 alunos, distribuídos por 30 turmas de 12 escolas públicas portuguesas" (p. 27), com idade entre 9 e 14 anos. Os autores não apresentam o nível socioeconômico dos participantes. Entre os resultados, destaca-se o de que o trabalho de casa "se pode assumir também como ferramenta essencial no sistema educativo, uma vez que parece contribuir quer direta quer indiretamente para o objetivo último da educação: preparar o indivíduo para aprender ao longo da vida" (p. 32).

\section{Discussão}

As atividades extracurriculares têm impactos significativos àqueles que participam delas (Mahoney, 2000; Mahoney, Harris \& Eccles, 2006). Isso aponta a necessidade de iniciar estudos brasileiros que visem a verificar se os dados encontrados em outros contextos se repetem no Brasil ou apontem resultados distintos. No entanto, permanece pouco conhecida a produção brasileira acerca dos efeitos de ações fora do contexto escolar para crianças e adolescentes. Pois, como pôde ser observado na descrição dos resultados deste estudo, a publicação acerca das atividades extracurriculares, pelo menos nos periódicos analisados, apresenta-se como embrionária. 
Em um universo de 1679 artigos, apenas 9 foram destacados, sendo 3 na revista "Psicologia: teoria e pesquisa", 4 na "Psicologia: reflexão e crítica" e 2 no periódico "Psicologia escolar e educacional". O número maior de publicações nas duas primeiras pode se justificar por serem editados há mais de 20 anos. Além disso, na "Psicologia: reflexão e crítica", em que aparece o maior número de artigos, há uma concentração maior de estudos relacionados à Psicologia do desenvolvimento, o que explica a maior incidência de trabalho nessa revista. Já na "Psicologia escolar e educacional", notou-se que, mesmo sendo um meio de divulgação dos trabalhos de Psicologia escolar e educacional, não houve uma aparição significativa. Ressalta-se que esse periódico é recente, e o número de artigos publicados é significativamente menor comparado aos outros dois. Porém foi o único periódico em que se pôde detectar trabalhos que se relacionam diretamente com as atividades extracurriculares, em sintonia com a definição apresentada neste artigo.

Destaca-se, ainda, o fato de que palavras-chave como programas, extracurricular(es), contraturno, extraescolar, projeto(s), ação socioeducativa, jornada ampliada, centros, ONGs, tempo integral não foram encontradas em nenhum título de trabalho. Esperava-se que surgisse algum artigo que tratasse de escolas ou de educação em tempo integral nos três periódicos, fato que não aconteceu. $\mathrm{O}$ que levou à ampliação da concepção de atividade extracurricular.

Observa-se que, em relação ao público participante das pesquisas, há destaques para faixas etárias específicas: 7 e 12 anos (Marturano, 1999; Poletto, Wagner \& Koller, 2004; Okano, Loureiro, Linhares, \& Marturano, 2004; Okano \& Loureiro, 2008), 9 a 14 anos (Cordeiro, Menezes \& Castro, 2002; Rosário, Baldaque, Mourão, Nuñez, González-Pienda et al., 2008), 13 a 17 anos (Bandeira, Koller, Hutz \& Forster, 1996), 12 a 18 anos (Sarriera, Tatim, Coelho, Busker, 2007) e 6 a 19 anos, como no estudo de Alencar, Feldhusen \& French (2004).

Em relação ao nível socioeconômico dos sujeitos das pesquisas, observase que Alencar, Feldhusen \& French (2004) e Rosário, Baldaque, Mourão, Nuñez, González-Pienda et al. (2008) não realizam esse destaque. Já no trabalho de Okano \& Loureiro (2008), observa-se que os pesquisados são de classe média (C). Seis entre os nove artigos levantados realizaram suas pesquisas com participantes de nível socioeconômico baixo (Marturano, 1999; Poletto, Wagner \& Koller 2004; Bandeira, Koller, Hutz \& Forster, 1996; Cordeiro, Menezes \& Castro 2002; Okano, Loureiro, Linhares \& Marturano, 2004; Sarriera, Tatim, Coelho, Busker, 2007), que se caracterizam com algum aspecto de vulnerabilidade no seu desenvolvimento. O que demonstra uma atenção 
às pessoas desse nível socioeconômico, e esses estudos apontam, em alguma medida, que esse público pode se beneficiar de atividades extracurriculares estruturadas em sintonia com o estudo de Mahoney (2000). Porém esse recorte remete ao fato de que atividades extracurriculares destinam-se apenas aos menos favorecidos economicamente, com a premissa de que essas açóes devem apenas proteger o público que participa delas, e não também impactar no seu desenvolvimento.

Observa-se que aparece, de forma incipiente, a investigação sobre os efeitos de programas ligados a políticas públicas, em horário alternado ao da escola, aos seus participantes e do destaque da necessidade de investimento em ações como essas nos trabalhos de Okano \& Loureiro (2008); Sarriera e cols. (2007); Okano, Loureiro, Linhares \& Marturano (2004). É importante lembrar a necessidade de que estas não sejam uma repetição do espaço escolar e que visem a aprendizagens para além desse contexto. Ou seja, que não haja somente reforço escolar.

Notou-se, nos estudos levantados, que há trabalhos que apontam impactos positivos de atividades extracurriculares, como o para casa e programas psicopedagógicos, no desempenho acadêmico (Marturano, 1999; Okano \& Loureiro, 2008; Rosário, Baldaque, Mourão, Nuñez, González-Pienda et al., 2008), em aspectos comportamentais (Okano \& Loureiro, 2008; Bandeira, Koller, Hutz \& Forster, 1996) e da importância dessas açôes na prevenção de problemas de aprendizagem e com o não envolvimento com a violência e consumo de drogas ilícitas e lícitas (Okano, Loureiro, Linhares, \& Marturano, 2004; Tatim, Coelho, Busker, 2007), para a possibilidade de facilitar a inserção no mercado de trabalho (Bandeira, Koller, Hutz \& Forster, 1996). Esses achados corroboram os encontrados em estudos internacionais que investigaram os impactos das atividades extracurriculares nesses aspectos, como os de Posner e Vandell (1994, 1999), Mahoney (2000) e Cooper, Valentine, Ney \& Lindsay (1999).

\section{Considerações finais}

As pontuações apresentadas por Mahoney, Harris e Eccles (2006) foram responsáveis pela elaboração deste trabalho e de outro, que buscou estudos sobre atividades extracurriculares em âmbito internacional (Matias, 2007). Tinha-se como "hipótese" de que iriam ser destacados diversos estudos brasileiros com foco nas açôes para além da escola, de programas sociais que atendem crianças e adolescentes em horário alternado ao da escola, ou ao menos de escolas de tempo integral, devido à alta incidência de projetos em 
execução nesse sentido no País. No entanto, não foi isso que se encontrou, nem mesmo em pesquisas exploratórias em outros periódicos, bases de dados como o portal de periódicos da CAPES, Scielo e Bvs-psi ${ }^{1}$. O que destaca a hipótese de que não há pesquisadores investigando os efeitos das atividades extracurriculares no Brasil.

Sabe-se da limitação dos dados apresentados neste estudo e que é possível que haja trabalhos que visem a detectar os impactos das atividades extracurriculares no País. Uma possibilidade é de que estes estejam concentrados em dissertações e teses de programas de pós-graduação e ainda não foram transformados em artigos e publicados. Porém o objetivo principal deste trabalho foi o de chamar a atenção para o fato de que é preciso um investimento em pesquisas que foquem os efeitos dos programas extracurriculares nos seus participantes.

A justificativa para isso é que, se as escolas de tempo integral ou programas extracurriculares são importantes, deve haver um investimento maior por parte do poder público em ações nesse sentido e é melhor que estas sejam elaboradas a partir de dados levantados em pesquisas do que das ideias dos gestores públicos. Eles precisam de conhecimentos sobre as condições que afetam o desenvolvimento infantil e adolescente, e as pesquisas psicológicas podem contribuir nesse sentido. Além disso, observa-se uma tendência à implantação de escolas de tempo integral no País. Já que serão conjugados esforços nesse sentido (Brasil, 1997), que estes estejam embasados e permeados pelo caráter não só da "proteção" dos estudantes, mas também pelo impacto no desenvolvimento deles como um todo, o que destaca o quanto podem ser úteis as pesquisas empíricas sobre as atividades extracurriculares e do seu caráter de urgência para uma educação em tempo integral com impactos profícuos.

\section{Referências}

Alencar, E. M. L. S.; Feldhusen, J. F. \& French, B. (2004). Identificando talentos, aspirações profissionais e pessoas mais admiradas por estudantes. Psicologia escolar e educacional, 8 (1), 11-16.

Bandeira, D. R.; Koller, S. H; Hutz, C. S. \& Forster,L. (1996). Desenvolvimento psicossocial e profissionalização: uma experiência com adolescentes de risco. Psicologia: reflexão e crítica, 9 (1), 185-207.

${ }^{1}$ www.periodicos.capes.gov.br; www.scielo.br; www.bvs-psi.org.br. 
Bardin, L. (1988). Análise de conteúdo. (L. A. Reto \& A. Pinheiro, Trad.). Lisboa: Edições 70.

Brandão, Z. (1989). A escola de $1^{\circ}$ grau em tempo integral: "as lições da prática”. Educação \& Sociedade, 10 (32), 116-129.

Brasil. Presidência da República (1996, dez 23). Lei n.o 9.394, de 20 de dezembro de 1996. Estabelece as diretrizes e bases da educação nacional. Diário Oficial da União. Disponível em: <http://www.planalto.gov.br/ ccivil_03/LEIS/19394.htm> Acesso em: 5 maio 2008.

Carvalho, M. C. B. \& Azevedo, M. J. (2005). Ações socioeducativas no âmbito das políticas públicas. In: Centro de Estudos e Pesquisas em Educação. Avaliação: construindo parâmetros das açôes socioeducativas. (pp. 25-33). São Paulo: Cenpec.

Cavaliere, A. M. \& Coelho, L. M. (2003). Para onde caminham os CIEPs? Uma análise após 15 anos. Cadernos de Pesquisa, 119, 147-174.

Centro de Estudos e Pesquisas em Educação, Cultura e Ação Comunitária. (2003). Muitos lugares para aprender. São Paulo: Cenpec.

Cooper, H.; Valentine, J. C.; Ney, B. \& Lindsay, J. J. (1999). Relationships between five after-school activities and academic achievement. Journal of Educational Psychology, 91 (2), 369-378.

Cordeiro, A. C. F.; Menezes, J. A. \& Castro, L. R. (2002). Oficinas da cidade em Fortaleza. Psicologia: reflexão e crítica, 15 (1), 53-61.

Costa, M.A. (1991). Comparação das estimativas do custo/aluno em dois CIEPs e duas escolas convencionais do Município do Rio de Janeiro. Educação \& Sociedade, 14 (40), 486-501.

Eccles, J. S.; Barber, B. L.; Stone, M. \& Hunt, J. (2003). Extracurricular activities and adolescent development. Journal of Social Issues, 59 (4), 865-889.

Giovanni, G. \& Souza, A. N. (1999). Criança na escola? Programa de formação integral da criança. Educação \& Sociedade, 20 (67), 70-111.

Guará, I. M. F. R. Educação integral: articulação de projetos e espaços de aprendizagem. Centro de Estudos e Pesquisas em Educação, Cultura e Ação Comunitária. Disponível em: <http://www.cenpec.org.br/modules/xt_ conteudo/index.php?id=46>. Acesso em: 6 maio 2007. 
Kramer, S. (1991). CIACs: falácias, equívocos e tentações. Educação \& Sociedade, 14 (40), 461-474.

Mahoney, J. L.; Harris, A. L. \& Eccles J. S. (2006). Organized activity participation, positive youth development, and the over-schedullin hypothesis. Social Policy Report: Giving Child and Youth Development Knowledge Away, 20 (4), 3-30.

Mahoney, J. L. \& Cairns, R. B. (1997). Do extracurricular activities protect against early school dropout? Developmental Psychology, 33 (2), 241-253.

Mahoney, J. L. (2000). School extracurricular activity as moderator in the development of antisocial patterns. Child Development, 71 (2), 502-516.

Marturano, E. M. (1999). Recursos no ambiente familiar e dificuldades de aprendizagem na escola. Psicologia: teoria e pesquisa, 15 (2), 135-142.

Matias, N. F. C. (2007). Políticas públicas para além da escola: um levantamento bibliográfico sobre atividades extracurriculares. Monografia. Universidade Federal de Minas Gerais, Faculdade de Filosofia e Ciências Humanas, Departamento de Ciência Política, Belo Horizonte.

Mignot, A. C. V. (1991). A escola pública e a construção de um espaço alternativo de educação. Educação \& Sociedade, 14 (40), 502-508.

Okano, C. B. \& Loureiro, S. R. (2008). Suporte psicopedagógico na escola: estudo de seguimento com escolares. Psicologia: teoria e pesquisa, 24 (3), 287 294.

Okano, C. B.; Loureiro, S. R.; Linhares, M. B. M. \& Marturano, E. M. (2004). Crianças com dificuldades escolares atendidas em programa de suporte psicopedagógico na escola: avaliação do autoconceito. Psicologia: reflexão e crítica, 17 (1), 121-128.

Pierce, K. M.; Hamm, J. V. \& Vandell, D. L. (1999). Experiences in afterschool programs and children's adjustment in first-grade classrooms. Child Development, 70 (3), 756-767.

Poletto, M.; Wagner, T. M. \& Koller, S. H. (2004). Resiliência e desenvolvimento infantil de crianças que cuidam de crianças: uma visão em perspectiva. Psicologia: teoria e pesquisa, 20 (3), 241-250.

Pont, Raul; Fontenelle, Maria Luiza \& Bernardi, Celso. (1991). Projeto 
Minha Gente: CIACs - Centros Integrados de Apoio à Criança. Educação \& Sociedade, 14 (40), 475-485.

Posner, J. K. \& Vandell, D. L. (1994). Low-income children's after-school care: are there beneficial effects of after-school programs? Child Development, 65, 440-456.

Posner, J. K. \& Vandell, D. L. (1999). After-school activities and the development of low-income urban children: a longitudinal study. Development Psychology, 35 (3), 868-879.

Rosário, P. S. L.; Baldaque, M.; Mourão, R.; Nuñez, J. C.; González-Pienda, J. A. et al. (2008). Trabalho de casa, autoeficácia e rendimento em matemática. Psicologia escolar e educacional, 12 (1), 23-35.

Sarriera, J. C.; Tatim, D. C.; Coelho, R. P. S.; Busker, J. (2007). Uso do tempo livre por adolescentes de classe popular. Psicologia: reflexão e crítica, 20 (3), 361-367.

Soares, J. F. (2007). Melhoria do desempenho cognitivo dos alunos do ensino fundamental. Cadernos de Pesquisa, 37 (130), 135-160. 